\title{
Correction to: Segregation of a novel p.(Ser270Tyr) $M A F$ mutation and p.(Tyr56*) CRYGD variant in a family with dominantly inherited congenital cataracts
}

\author{
Lubica Dudakova $^{1} \cdot$ Viktor Stranecky $^{1} \cdot$ Olga Ulmanova $^{2} \cdot$ Eva Hlavova $^{3} \cdot$ \\ Marie Trková $^{3} \cdot$ Andrea L. Vincent $^{4} \cdot$ Petra Liskova $^{1,5}$
}

Published online: 10 October 2017

(C) Springer Science+Business Media B.V. 2017

\section{Correction to: Mol Biol Rep \\ DOI 10.1007/s11033-017-4121-4}

There was a spacing error in the initial online publication, and there were errors in the Acknowledgments section. The original article has been updated.

The online version of the original article can be found under doi:10.1007/s11033-017-4121-4.

Petra Liskova

petra.liskova@lf1.cuni.cz

1 Institute of Inherited Metabolic Disorders, First Faculty of Medicine, Charles University and General University Hospital in Prague, Ke Karlovu 2, 12808 Prague,

Czech Republic

2 Department of Neurology and Centre of Clinical Neuroscience, First Faculty of Medicine, Charles University and General University Hospital in Prague, Katerinska 30, 12821 Prague, Czech Republic

3 Gennet, Centre for Fetal Medicine and Reproductive Genetics, Kostelni 9, 17000 Prague, Czech Republic

4 Department of Ophthalmology, FMHS, New Zealand National Eye Centre, University of Auckland, 85 Park Rd, Grafton, Auckland 1023, New Zealand

5 Department of Ophthalmology, First Faculty of Medicine, Charles University and General University Hospital in Prague, U Nemocnice 2, 12808 Prague, Czech Republic 